\title{
ANÁLISE COMPARATIVA DA PRODUÇÃO DE SERAPILHEIRA EM FRAGMENTOS ARBÓREOS E ARBUSTIVOS EM ÁREA DE CAATINGA NA FLONA DE AÇU-RN ${ }^{1}$
}

\author{
Caio César de Azevedo Costa ${ }^{2}$, Ramiro Gustavo Valera Camacho ${ }^{3}$, Iron Dantas de Macedo ${ }^{4}$ e Paulo \\ César Moura da Silva ${ }^{4}$
}

\begin{abstract}
RESUMO - A serapilheira compreende a camada mais superficial do solo em ambientes florestais, sendo formada por folhas, ramos, órgãos reprodutivos e detritos, que exercem inúmeras funções no equilíbrio e dinâmica dos ecossistemas florestais. O objetivo deste trabalho foi avaliar a produção de serapilheira em ambientes arbóreo e arbustivo em uma área preservada no bioma Caatinga. A pesquisa foi realizada na Floresta Nacional do Açu-RN, a qual foi dividida em dois setores distintos, um setor arbóreo e outro arbustivo. Foram realizadas 12 coletas mensais da serapilheira. Em cada um dos setores, foram instalados 20 coletores de madeira medindo 1,0 m x 1,0 m x 0,15 m (0,15 m³) e com fundo de tela de náilon de malha $1 \mathrm{~mm}$, distribuídos de forma aleatória na área da Flona. O material coletado foi acondicionado em sacos de papel, identificado e conduzido ao Laboratório Zoobotânico da UERN. O material foi secado em estufa de circulação de ar forçada a $70{ }^{\circ} \mathrm{C}$ durante $72 \mathrm{~h}$. As médias de todas as variáveis foram expressas em $\mathrm{g} / \mathrm{m}^{2} \mathrm{e}$ submetidas à análise de variância e ao teste $\mathrm{t}$ $(\mathrm{p}<0,05)$. A quantidade de serapilheira produzida nas áreas da Caatinga estudada foi de $2.984,5 \mathrm{~kg} / \mathrm{ha}$, tendo sido estimados $3.384 \mathrm{~kg} / \mathrm{ha}$ no setor arbóreo e $2.580 \mathrm{~kg} / \mathrm{ha}$ no setor arbustivo. Os valores entre os setores não apresentaram diferença em relação à serapilheira produzida. O padrão de deposição da serapilheira acompanhou a sazonalidade da Caatinga, onde os períodos de maior produção ocorreram logo após o período chuvoso, na área de estudo.
\end{abstract}

Palavras-chave: Caatinga, Serapilheira e Arbóreo-arbustivo.

\section{COMPARATIVE ANALYSIS OF LITTER PRODUCTION IN SHRUB-TREES FRAGMENTS IN A CAATINGA AREA OF FLONA AÇU-RN.}

\begin{abstract}
The litter is the most superficial layer of soil in a forest environment, it's composed by Leaves, Twigs, seeds, roots and remains, which together have innumerous importance in establishing and balancing the ecosystem. The purpose of this work was to evaluate the litterfall in two different areas, shrubs and treed, in a preserved area of biom caatinga. This research was carried out in the Açu Nacional Forest - FLONA/ $A C ̧ U-R N$. The FLONA was divided in two different areas, in relation to aspects and vegetation postage, for shrubs and trees. 12 litter collections were made. Each area had 20 wooden traps installed measuring $1.0 \mathrm{~m}$ $X 1.0 \mathrm{~m} X 0.15 \mathrm{~m}(0.15 \mathrm{~m} 3)$, with $1 \mathrm{~mm}$ nylon mesh, distributed at random in the Flona's area. The material collected was put in paper bags, named and taken to the UERN botanic lab. The material was oven-dried at $70^{\circ} \mathrm{C}$ during $72 \mathrm{~h}$ and weighed. The results were expressed in $\mathrm{g} / \mathrm{m} 2$ and submitted to the analysis of variance and test $t(p<0.05)$. The source results showed that the average annual litterfall was estimated at 2,984.5 $\mathrm{Kg} / \mathrm{ha}$, with an estimated 3,384 Kg/ha in tree vegetation and 2,580 kg/ha in shrub vegetation. The litterfall in caatinga bioma was similar to other sources in the caatinga areas. The highest values of litterfall were observed after rainy seasons and the beginning of dry seasons in the researched area.
\end{abstract}

Key words: Caatinga, Litter and Shrub-trees.

\footnotetext{
${ }^{1}$ Recebido em 06.03.2008 e aceito para publicação em 14.10.2009.

${ }^{2}$ Universidade Potiguar, Brasil. E-mail: <caiocesar.costa@ibest.com.br>.

${ }^{3}$ Universidade do Estado do Rio Grande do Norte, UERN, Brasil. E-mail: <ramirogustavo@uern.br>.

${ }^{4}$ Universidade Federal Rural do Semi-Árido, UFERSA, Brasil.
} 


\section{INTRODUÇÃO}

A serapilheira compreende a camada mais superficial do solo em ambientes florestais, sendo formada por folhas, ramos, órgãos reprodutivos e detritos, que exercem inúmeras funções no equilíbrio e dinâmica desses ecossistemas.

Segundo Vital (2004), a serapilheira é considerada um dos meios mais importantes na transferência de nutrientes essenciais da vegetação para o solo. Moço et al. (2005) explicaram que em seu conteúdo há grande diversidade de invertebrados que compõem a fauna edáfica que está diretamente relacionada com a fragmentação e decomposição desse material fertilizando naturalmente os solos.

A geração de informações sobre a deposição de serapilheira e análise do seu conteúdo são importantes ferramentas para a compreensão e conservação dessas áreas, bem como suas inter-relações com o meio. Selle (2007) relatou que, com a remoção das florestas, essas inter-relações são quebradas, acarretando perda da biodiversidade e da fertilidade dos solos.

Maia (2004) mostrou a importância da serapilheira no que diz respeito não só à proteção e fertilização do solo, mas também importantíssimo para conservar a biodiversidade que ali se encontra.

A quantidade de serapilheira e seu conteúdo de nutrientes que são aportados ao solo pelo povoamento irão refletir na sua capacidade produtiva e no seu potencial de recuperação ambiental, tendo em vista as modificações que irão ocorrer nas características físicas do solo e, consequentemente, na cadeia alimentar resultante do material orgânico adicionado ao solo (SCHUMACHER et al., 2004; KONIG et al., 2002).

Na pesquisa sobre produção de serapilheira, destaca-se a importância desse material na conservação e manutenção natural dos ecossistemas florestais. Uma vez que, além dos processos naturais de ciclagem, esse material abriga em seu conteúdo grande quantidade de sementes em estado de dormência. Este estudo pode ser utilizado como um dos subsídios básicos para o manejo florestal, bem como para a detecção de distúrbios de origens natural e antrópica.

A Caatinga é o tipo de vegetação que caracteriza o Nordeste semiárido. E um tipo de vegetação peculiar adaptada às condições edafoclimáticas do semiárido brasileiro. Apesar de sua grande heterogeneidade e endemismo, é um dos biomas mais desconhecidos do país (JOLY et al., 1999).

Rodal (2002) relatou que vários sistemas de classificação da vegetação individualizam-na por ocupar área contínua, com clima quente e semiárido, circundada por áreas de clima mais úmido e apresentar porção significativa de espécies endêmicas. As características vegetacionais do bioma não são uniformes em toda a sua extensão, uma vez que os fatores ambientais mudam ao longo de sua área, alterando as características bióticas.

Andrade Lima (1981) observou que, em termos da classificação da vegetação do domínio das caatingas, duas questões são inegavelmente claras: 1) os diferentes tipos vegetacionais resultam da interação clima-solo, em que o número de combinações e, consequentemente, o número de comunidades vegetais são muito altos; e 2) as informações sobre a relação vegetação/fatores físicos não são suficientemente conhecidas.

A Caatinga, nos vários aspectos que apresenta, é constituída essencialmente de árvores e arbustos espinhentos (que perdem suas folhas na estação seca), de plantas suculentas espinhosas e de plantas herbáceas que se desenvolvem com bastante vigor depois das chuvas (BRASIL, 1977).

A morfologia, fisiologia e ecologia das plantas da Caatinga determinam as características vegetacionais do bioma. As espécies possuem caráter comportamental e fisiológico em relação às características do meio, determinando, dessa forma, as peculiaridades e ajustamento das plantas com as características físicas do meio em questão. Assim, os processos biológicos, dado o comando genético, selecionaram peculiaridades adaptativas, tornando a flora endêmica da Caatinga compatível com as condições severas a que estão sujeitos os táxons. Essas peculiaridades adaptativas da vegetação são determinadas, principalmente, pela temperatura e disponibilidade de água. O estresse hídrico é um dos fatores mais limitantes de produtividade e distribuição geográfica das espécies vegetais.

As Florestas Nacionais (FLONA) são unidades de conservação de uso sustentável (uso direto), constituindo áreas públicas que possuem extensa cobertura vegetal, nativa ou plantada, estabelecida com o objetivo de controlar o manejo dos recursos naturais, com ênfase na produção de madeira e na proteção 
dos recursos hídricos e sítios históricos e arqueológicos (BRASIL, 2002). Porém, ainda são Unidades de Conservação (UCs) em um número muito reduzido, diante da necessidade dessa categoria para o bioma Caatinga. Atualmente, o Brasil conta com 63 FLONAS, sendo seis na Região Nordeste e apenas duas no bioma Caatinga (BRASILOESTE, 2006).

A Floresta Nacional do Açu (FLONA-Açu) representa um remanescente de floresta de Caatinga, mantendo ainda preservada boa parte de suas características originais. É uma unidade de conservação que exerce grande importância econômica e cultural para o Município de Açu, tanto pela conquista de uma área preservada em nível nacional quanto pela sua exuberância de biodiversidade.

As informações sobre a estrutura e funcionamento de ecossistemas florestais como a Caatinga ainda são escassas. É sabido que tais estudos, produção e decomposição do folhedo, são fundamentais para o conhecimento das características funcionais dos ecossistemas e, por conseguinte, de sua resistência a diversos fatores de tensão decorrentes, sobretudo, da atividade humana.

Este estudo teve como principais objetivos avaliar a produção de serapilheira em uma área preservada do bioma Caatinga e comparar a produção anual desse folhedo em dois setores da FLONA na cidade de Açu-RN, um arbóreo e outro arbustivo.

\section{MATERIAL E MÉTODOS}

\subsection{Localização e descrição da área}

A pesquisa foi realizada na Floresta Nacional do Açu, a qual, segundo a divisão do IBGE, se insere na Microrregião do Vale do Açu e na Zona Homogênea do Planejamento Mossoroense. O Município de Açu está localizado a $5^{\circ} 34^{\prime}$ de latitude sul e a $36^{\circ} 54^{\prime}$ de longitude oeste, com altitude média de $100 \mathrm{~m}$. A FLONA representa um remanescente de floresta de Caatinga, mantendo ainda preservada boa parte de suas características originais.

O clima do local, segundo a classificação de Köeppen, é “Bswh”, ou seja, seco, muito quente e com estação chuvosa de março a abril, com variações de 1,4 mm a 1.627,1 mm e média de precipitação anual de $585,8 \mathrm{~mm}$. A temperatura média anual é de $28,1^{\circ} \mathrm{C}$ e umidade relativa média anual de 70\% (BRASIL, 2006b).
Em relação às características da vegetação, a FLONA é caracterizada como ecossistema típico de Caatinga hiperxerófila, com aspecto fisionômico marcado por formação vegetal do tipo arbóreo-arbustiva, encontrando-se plantas de grande porte em alguns pontos da mata e predomínio de espécies arbustivas em outros. Na área da FLONA é possível identificar dois setores distintos com relação à característica da vegetação, um com vegetação de maior porte e densidade (setor arbóreo) e outro com vegetação mais baixa e de menor porte (setor arbustivo).

A localização dos tipos vegetacionais presentes na FLONA seguiram a classificação proposta por Andrade Lima (1981), em que se levaram em consideração a heterogeneidade da cobertura vegetal da área e os dados florísticos.

O setor arbóreo localiza-se entre os pontos $5^{\circ} 34^{\prime}$ $43^{\prime \prime}$ ' $36^{\circ} 56^{\prime} 27^{\prime \prime}$ 'W e 5 $34^{\prime} 37^{\prime \prime}$ de latitude sul e $36^{\circ}$ 56' 40', de longitude oeste, possui vegetação que se caracteriza por um estrato arbóreo denso e com espécies vegetais que atingem até $15 \mathrm{~m}$ de altura. De acordo com a classificação de Andrade-Lima (1989), esse setor se enquadra na unidade II, que representa as típicas caatingas florestais.

Nesse setor é possível identificar como táxons predominantes: catingueira (Caesalpinia pyramidalis), catanduva (Piptadenia moniliformis), pau-branco (Auxemma oncocalix), sabiá (Mimosa caesalpinifolia), angico (Anadenanthera macrocarpa), imburana (Bursera leptophloes) facheiro (Pilosocereus piauhiensis) e mandacaru (Cereus jamacaru).

O setor arbustivo localiza-se entre os pontos $5^{\circ}$

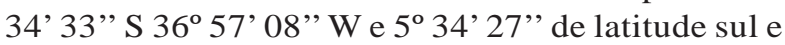
$36^{\circ} 57^{\prime} 19^{\prime \prime}$ de longitude oeste. Representa um tipo de Caa-tinga arbustiva espalhada em pequenas manchas na área da FLONA. Possui vegetação baixa que atinge um máximo de 3 a $4 \mathrm{~m}$ de altura, enquadra-se dentro da V unidade vegetal de acordo com a classificação de Andrade-Lima (1989). Possui como táxons predominantes: jurema-branca (Piptadenia stipulaceae), mofumbo (Combretum leprosum), marmeleiro (Croton sonderianus), feijão-bravo (Capparis cynophallophora) e ameixa (Ximenia americana).

\subsection{Estudo da serapilheira}

O estudo foi realizado ao longo de um ano (novembro/2004 a outubro/2005), acompanhando as alterações no tempo, período chuvoso e estiagem na

R. Árvore, Viçosa-MG, v.34, n.2, p.259-265, 2010 
Caatinga. Em cada um dos setores foram instalados 20 coletores de madeira medindo 1,0 m x 1,0 m x $0,15 \mathrm{~m}\left(0,15 \mathrm{~m}^{3}\right)$ cada e com fundo de tela de náilon de malha $1 \mathrm{~mm}$, distribuídos na área da FLONA. A malha tem a função de acondicionar o material formador da serapilheira sem permitir o acúmulo de água, evitando que se inicie o processo de decomposição do material no período chuvoso (COSTA et al., 2007).

Os coletores foram instalados em 30 de outubro de 2004 (estação seca), e a partir do dia 30 de novembro de 2004 a serapilheira foi coletada mensalmente até o final do experimento, no dia 30 de novembro de 2005, fechando o ciclo anual de acompanhamento da produção da biomassa vegetal (período seco e chuvoso). Os coletores ficaram distanciados cerca de $100 \mathrm{~m}$ entre si, ao longo de um transecto determinado.

O material de cada coletor foi acondicionado em sacos de papel identificado com relação à área e conduzido ao Laboratório Zoobotânico da Universidade do Estado do Rio Grande do Norte. O material coletado foi secado em estufa de circulação de ar forçada a $70{ }^{\circ} \mathrm{C}$, durante $72 \mathrm{~h}$, para se obter o peso de matéria seca da biomassa vegetal e, depois, separado em folhas, ramos (galhos e cascas), órgãos reprodutivos (flores, frutos e sementes) e detritos (fragmentos de invertebrados e fezes de animais), os quais foram pesados em balança eletrônica com precisão de 1 g, com o objetivo de avaliar a contribuição de cada uma das frações por área de estudo. As médias foram expressas em $\mathrm{g} / \mathrm{m}^{2}$ e submetidas à análise de variância e ao teste $t(p<0,05)$.

\section{RESULTADOS}

A quantidade total de serapilheira produzida (30/ 11/2004 a 30/10/2005) foi estimada em $3.384 \mathrm{~kg} / \mathrm{ha} / \mathrm{ano}$ no setor arbóreo e 2.580 kg/ha/ano no setor arbustivo, entretanto não apresentou diferença estatística significativa entre os setores $(\mathrm{p}<0,05)$.

As médias indicaram maior padrão de deposição no setor arbóreo, porém, estatisticamente, a proximidade das médias obtidas principalmente nos meses de menor e maior deposição do folhedo mostrou similaridade na produção da serapilheira nos dois setores, com exceção dos meses de dezembro de 2004 e agosto de 2005, como mostrado na Figura 1.

R. Árvore, Viçosa-MG, v.34, n.2, p.259-265, 2010

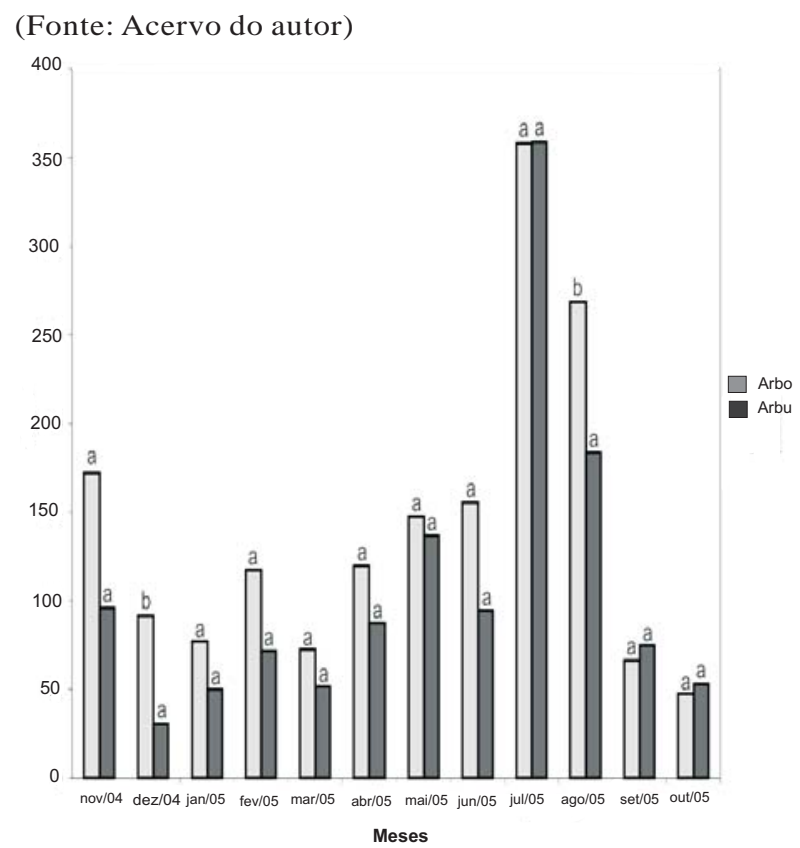

Figura 1 - Produção mensal de serapilheira nos setores arbóreo e arbustivo da Floresta Nacional do Açu. FLONAAçu, Açu, RN - 2004 e 2005.

Figure 1 - Monthly production of litter fall in shrub and treed areas of the National Forest of Açu. FLONAAçu, Açu, RN - 2004 e 2005.

\section{DISCUSSÃO}

Os valores médios mensais e respectivos errospadrão do peso da matéria seca formadora da serapilheira produzida nos setores arbóreo e arbustivo da FLONA são apresentados na Tabela 1.

Embora numericamente inferior em quase todos os meses, com exceção dos meses de julho, setembro e outubro de 2005, o setor arbustivo produziu estatisticamente a mesma quantidade de serapilheira em relação ao setor arbóreo na Caatinga estudada.

Em relação ao folhedo produzido em ambientes de Caatinga, os valores obtidos são maiores do que os dos trabalhos já realizados nesse bioma.

Alves (2006), em acompanhamento da produção de serapilheira em uma área de Caatinga arbustiva densa, realizado no semiárido paraibano, observou 899,2 kg/ha/ano. De maneira análoga, na Tabela 2 são apresentados os valores médios mensais e respectivos erros-padrão da fração folhas da serapilheira produzida. A fração folhas perfaz 65\% do material formador da 
Tabela 1 - Valores mensais médios de serapilheira e respectivos erros-padrão nos dois setores da FLONA.

Table 1 - Medium monthly values of litter fall and their standards of error in two areas of FLONA.

\begin{tabular}{lccc}
\hline Meses & Setor Arbóreo & Setor Arbustivo & Prob. teste t \\
\hline Nov/04 & $34,45 \pm 7,73$ & $19,15 \pm 3,79$ & $0,08^{\text {ns }}$ \\
Dez/04 & $18,35 \pm 3,11$ & $6,20 \pm 1,72$ & $0,01^{* *}$ \\
Jan/05 & $15,45 \pm 2,79$ & $10,05 \pm 4,37$ & $0,30^{\text {ns }}$ \\
Fev/05 & $23,50 \pm 3,99$ & $14,35 \pm 2,56$ & $0,06^{\text {ns }}$ \\
Mar/05 & $14,40 \pm 2,60$ & $10,40 \pm 5,43$ & $0,51^{\text {ns }}$ \\
Abr/05 & $24,00 \pm 5,66$ & $17,50 \pm 3,87$ & $0,35^{\text {ns }}$ \\
Mai/05 & $29,55 \pm 4,66$ & $27,35 \pm 2,91$ & $0,69^{\text {ns }}$ \\
Jun/05 & $31,05 \pm 7,75$ & $18,95 \pm 2,79$ & $0,15^{\text {ns }}$ \\
Jul/05 & $71,70 \pm 11,25$ & $71,80 \pm 12,58$ & $0,99^{\text {ns }}$ \\
Ago/05 & $53,70 \pm 6,33$ & $36,70 \pm 5,17$ & $0,04^{*}$ \\
Set/05 & $13,25 \pm 1,81$ & $15,00 \pm 3,37$ & $0,65^{\text {ns }}$ \\
Out/05 & $9,50 \pm 0,99$ & $10,55 \pm 1,96$ & $0,63^{\text {ns }}$ \\
\hline
\end{tabular}

* Valor significativo; e (ns) valor não significativo.

* Significant value; and (ns) non-significant value

serapilheira, contribuindo com grande parcela do folhedo produzido. As folhas são fundamentais nos processos de fotossíntese e transpiração vegetal, processos que demandam grande quantidade de água. Dessa forma, no período da estiagem na Caatinga as plantas perdem suas folhas como mecanismo adaptativo ao estresse hídrico a que estão submetidas.

As médias foram bastante variáveis dentro dos diferentes meses e entre os setores, porém apenas os meses de novembro, dezembro de 2004 e janeiro de 2005 apresentaram diferenças significativas. No mês de julho de 2005, mês de maior deposição de serapilheira, as médias foram muito próximas, evidenciando a similaridade na produção do folhedo nos dois setores.

Nos meses de novembro, dezembro de 2004 e janeiro de 2005, na fração folhas (Tabela 2) os valores superiores significativos na Caatinga arbórea em relação à arbustiva, nesses meses de estiagem, se devem à permanência de parte da copa foliar de algumas plantas de porte arbóreo presentes nesse setor, como Caesalpinia pyramidalis, Auxemma oncocalix, Spondia tuberosa e Piptadenia moniliformis. Dessa forma, a maior deposição da fração folhas no setor arbóreo, nos referidos meses, pode ser explicada em função do comportamento fisiológico e da florística que compõem esse estrato, em relação à fração foliar.

Na Caatinga, a produção média de serapilheira mostra-se muito similar entre os poucos trabalhos realizados em Caatingas arbóreas e arbustivas
Tabela 2 - Valores mensais médios de serapilheira da fração folhas e respectivos erros-padrão nos dois setores da FLONA - Açu, RN.

Table 2 - Medium monthly values of litter fall for pieces of leaves and their standards of error in two areas of FLONA - AçU, RN.

\begin{tabular}{lccc}
\hline Meses & Setor Arbóreo & Setor Arbustivo & Prob. teste t \\
\hline Nov/04 & $19,45 \pm 3,59$ & $8,70 \pm 1,68$ & $0,01^{*}$ \\
Dez/04 & $9,65 \pm 2,25$ & $3,60 \pm 1,18$ & $0,02^{*}$ \\
Jan/05 & $9,25 \pm 2,46$ & $3,15 \pm 0,85$ & $0,02^{*}$ \\
Fev/05 & $7,10 \pm 1,43$ & $5,15 \pm 1,15$ & $0,29^{\text {ns }}$ \\
Mar/05 & $5,75 \pm 0,76$ & $4,70 \pm 2,51$ & $0,69^{\text {ns }}$ \\
Abr/05 & $9,75 \pm 2,11$ & $4,80 \pm 2,05$ & $0,10^{\text {ns }}$ \\
Mai/05 & $15,45 \pm 2,58$ & $15,2 \pm 2,37$ & $0,94^{\text {ns }}$ \\
Jun/05 & $21,44 \pm 6,32$ & $6,10 \pm 1,11$ & $0,02^{\text {ns }}$ \\
Jul/05 & $72,11 \pm 9,85$ & $61,70 \pm 10,89$ & $0,48^{\text {n }}$ \\
Ago/05 & $46,45 \pm 5,95$ & $31,20 \pm 4,86$ & $0,05^{\text {ns }}$ \\
Set/05 & $10,47 \pm 1,57$ & $12,30 \pm 3,14$ & $0,60^{\text {ns }}$ \\
Out/05 & $6,65 \pm 0,80$ & $7,80 \pm 1,96$ & $0,59^{\text {ns }}$ \\
\hline
\end{tabular}

* Valor significativo; e (ns) valor não significativo.

* Significant value; and (ns) non-significant value

(SANTANA, 2005; SOUTO, 2006; ALVES, 2006). Em média, a produção de serapilheira nesse bioma gira em torno de 1.500 a $3.500 \mathrm{~kg} / \mathrm{ha} / \mathrm{ano}$, tanto em florestas arbóreas quanto em arbustivas, sendo esses valores determinados pelas características morfológicas e fisiológicas comuns das plantas que compõem o bioma.

A produção de serapilheira nos dois setores analisados (setores arbóreo e arbustivo) mostrou, com exceção dos meses de dezembro de 2004 e agosto de 2005, resultados semelhantes em relação ao folhedo produzido ao longo do ano. Tal comportamento pode ser explicado em função das adaptações morfológicas e fisiológicas das plantas da Caatinga. Apesar da diferença no aspecto da vegetação, essas plantas possuem características semelhantes. Árvores e arbustos de médio porte, folhas pequenas, muitas vezes adaptadas a espinhadeiros, xeromorfismo e acentuada caducifolia, foram as características determinantes dos resultados semelhantes obtidos nos dois setores analisados na FLONA de Açu.

Os resultados obtidos em relação ao comportamento da serapilheira em função da pluviosidade ocorrida durante o trabalho mostraram nítida relação entre a precipitação e o ciclo mensal de deposição da serapilheira. O padrão de deposição da serapilheira é diretamente influenciado pelas mudanças de tempo (períodos chuvoso e seco) ocorridas no bioma Caatinga. Notou-se, claramente, que os períodos de maior deposição

R. Árvore, Viçosa-MG, v.34, n.2, p.259-265, 2010 
de serapilheira ocorrem logo após o final do período chuvoso ("inverno" na denominação regional) e início da estiagem (Figura 2).

A precipitação total durante o período das coletas foi de 542,9 mm, o que representa 7,33\% a menos em relação à média anual, entretanto cerca de $70 \%$ dessa precipitação ocorreu em apenas três meses (março, abril e maio/2005). Isso evidencia a irregularidade nos índices pluviométricos, em que essa característica influenciou no padrão de deposição da serapilheira.

Os maiores picos de produção de serapilheira aconteceram nos meses de julho e agosto de 2005 (717,5 e $452 \mathrm{~kg} / \mathrm{ha}$, respectivamente), coincidindo com o início da estiagem anual característica do bioma Caatinga; houve depois queda progressiva até outubro, quando atingiu o menor valor (100,25 kg/ha), evidenciando-se, assim, o efeito da redução da umidade na produção da serapilheira.

Conforme Alves et al. (2006), na estação seca o pico de deposição da serapilheira seria ocasionado pela grande queda de folhas, provocada pelo término do período chuvoso característico da região.

Esse comportamento não é característico apenas da Caatinga. Segundo Meguro et al. (1979), a queda do folhedo nas florestas tropicais é, de modo geral, contínua, mas variável, apresentando pico máximo na estação menos chuvosa ou seca.

\section{(Fonte: Acervo do autor)}

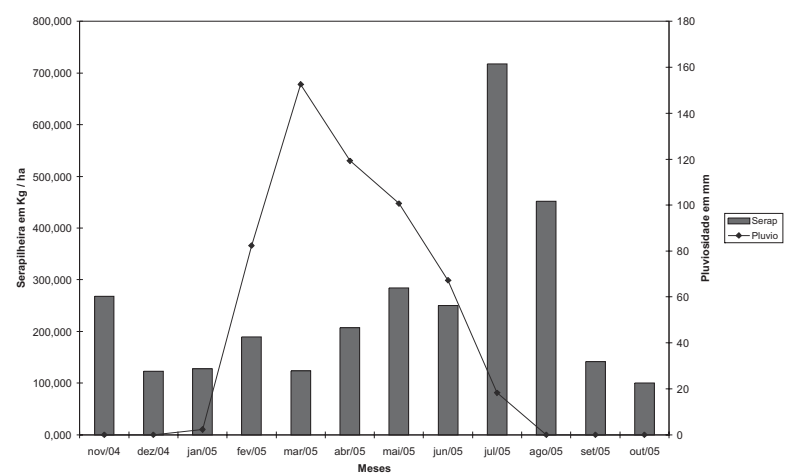

Figura 2 - Padrão de deposição mensal de serapilheira em relação à pluviosidade na FLONA-Açu, Açu, RN - 2004 e 2005.

Figure 2 - Monthly litterfall observed after the rainy season in FLONA-Açu, Açu, RN - 2004 to 2005.
A intensa caducifolia atrelada ao estresse hídrico caracteriza uma das principais adaptações fisiológicas nas plantas da Caatinga para suportar a estiagem anual. Nisso, a produção da serapilheira alcança seus maiores picos durante esse período do ano.

\section{CONCLUSÃO}

A produção de serapilheira na área estudada não apresentou diferença estatística significativa entre os setores arbóreo e arbustivo da FLONA.

O pico na produção de serapilheira ocorreu logo após o final do período chuvoso e o início da estiagem.

No entanto, sugerem-se a elaboração e realização de pesquisas em períodos mais longos, para a obtenção de uma gama de informações mais detalhadas e análises mais criteriosas da serapilheira na região semiárida nordestina.

\section{REFERENCIAS}

ALVES, A. R. et al. Aporte e decomposição de serapilheira em área de caatinga, na Paraíba. Revista de Biologia e Ciências da Terra. v. 6, $n^{\circ} 2,2^{\circ}$ semestre. 2006.

ANDRADE LIMA, D. The caatinga dominium. Revista Brasileira de Botânica, v.4, p.149-153, 1981.

ANDRADE LIMA, D. Plantas da caatinga. Rio de Janeiro: Academia Brasileira de Ciências, 1989. 243p.

BRASIL. Ministério do Meio Ambiente. Secretaria de Biodiversidades e Floretas. Diretoria do Programa Nacional de Áreas Protegidas. Sistema Nacional de Unidades de Conservação da Natureza - SNUC: lei $\mathrm{n}^{\circ}$ 9.985, de 18 julho de 2000; decreto $n^{\circ} 4.340$, de 2 de agosto de 2002. 2.ed.aum. Brasília: 2002. 52p.

BRASILOESTE. Disponível em <http:// www.brasiloeste.com.br/noticia/378> Acesso em 24 de janeiro de 2006 .

COSTA, C. C. A. et al. Produção de serapilheira na Caatinga da Floresta Nacional do Açú-RN. Revista Brasileira de Biociências. v. 5, supl. 1, p.246-248, 2007. 
INSTITUTO BRASILEIRO DE GEOGRAFIA E ESTATÍSTICA - IBGE. Clima. In: NIMER, E. (Ed): Geografia do Brasil. V. 2 Região Nordeste. Rio de Janeiro: 1977. 47-84p.

\section{INSTITUTO DO DESENVOLVIMENTO} ECONÔMICO E MEIO AMBIENTE DO RIO GRANDE DO NORTE - IDEMA. 2005. Disponível em: <http:/www.rn.gov.Br/ secretarias/idema/perfil/assu/assu.doc> . Acesso em 24 de jan. de 2006b.

JOLY, C. A. et al. Evolution of Brasilian phytogeography classification systems from the biodiverssity conservations point of view.

Ciencia \& Cultura, v.51, p.331-348, 1999.

KONIG, F. G. et al. Avaliação da sazonalidade da produção de serapilheira numa Floresta Estacional Decidual no município de Santa Maria-RS.

Revista Árvore, v.26, n.4, p.429-435, 2002.

MAIA, G. N. Caatinga arvores e arbustos e suas utilidades. São Paulo: D\&Z Computação 2004.

MOÇO, M. K. et al. Caracterização da fauna edáfica em diferentes coberturas vegetais na região norte fluminense. Revista Brasileira de Ciência do Solo, v.29, n.4, p.555-564, 2005.
MEGURO, M.; VINUEZA, G. N.; DELITTI, W. B. C. Ciclagem de nutrientes minerais na mata mesófila secundária- São Paulo 11 - O Papel da precipitação na importação e transferência de Potássio e Fósforo. Boletim de Botânica, v.7, p.61-67, 1979.

RODAL, M. J. N. Aspectos vegetacionais do bioma caatinga. biodiversidade. In: ARAÚJO, E. L. et al. (Eds.). Biodiversidade, conservação e uso sustentável da flora do Brasil. Recife: Universidade Federal Rural de Pernambuco/Sociedade de botânica do Brasil. Secção regional de Pernambuco, 2002. 44-45p.

SCHUMACHER, M. V. et al. Produção de serapilheira em uma floresta de Araucária angustifólia (Bertol) Kuntze no município de Pinhal Grande - RS. Revista Árvore, v.8, n.1, p. 29-37, 2004.

SELE, G. L. Ciclagem de nutrientes em ecossistemas florestais. Bioscience Journal, v.2, n.4, p.29-39, 2007.

VITAL, A. R. T. et al. Produção de serapilheira e ciclagem de nutrientes de uma floresta estacional semidecidual em zona ripárica. Revista Árvore, v. 28, n 6, p.793-800, 2004. 
